\title{
The Importance of Asset Allocation, Investment Policy and Active Management in Explaining Turkish Pension Fund Return Variations ${ }^{1}$
}

\author{
Nazlı Kalfa Baş \\ Managing Partner \\ Ludens Advanced Financial Services \\ Turkey \\ Serra Eren Sarığlu \\ Department of Finance \\ School of Business \\ Istanbul University \\ Turkey
}

\begin{abstract}
Which one is more important in explaining the return variations of pension funds? Market movement, asset allocation policy or active management? We explore the subject for Turkish equity and balanced pension funds for the period July 2007 to July 2017. This paper sheds a new light on pension funds' sources of performance from an emerging market perspective. Our first empirical investigation confirms the widely held belief that market movement is the dominant factor and leaves a little room for active management. However, the effect of the dominance changes depending on the pension fund category. The less restricted funds in their investment decisions perform higher active management ability. Our second and more refined analysis which removes the dominance of market movement component of total return, reveal a different picture. Our findings show that the active management and asset allocation have nearly an equal amount of explanatory power on the variations of balanced pension fund returns. However, for the equity pension funds does the active management provide a significantly higher performance than asset allocation policy.
\end{abstract}

Keywords: Asset allocation policy, active management, pension funds, Turkey

\section{Introduction}

Investigating the sources of portfolio performance has always been important. The relative importance of macrolevel decisions, which are related to the asset allocation of the portfolio, and micro-level decisions, called active management, in explaining return variation are still being discussed. The findings of Brinson, Hood and Beebower (1986) (henceforth BHB) pioneering article showed that asset allocation policy has an explanatory power of 93.6 per cent of total return variations. In a subsequent study, Brinson, Hood and Beebower (1991) confirmed their previous result. However, these articles have been subject to the criticism that the naive portfolio used in the examination of the importance of the asset allocation policy consists of 100 per cent cash. Hensel, Ezra and Ilkiw (1991) and Ibbotson and Kaplan (2000) pointed out that investmentpolicy becomes relatively unimportant if a diversified mix, rather than T-bills, is chosen as the naïve portfolio. Similar findings were obtained by Vardharaj and Fabozzi (2007).

Unlike the others, Xiong et al. (2010) examined the regression between total returns and policy returns in excess of market returns. In this way, the impact of market movement over time on total mutual fund returns is eliminated. This study shows that 80 per cent of total returns are explained by market movements. The other components of portfolios' total returns (asset allocation policy and active management) are equally important.

\footnotetext{
${ }^{1}$ The findings of this article have been represented in "Emeklilik Fonları Performans Raporu, Aralık 2017". This is a semiannual report prepared by Ludens Advanced Financial Services. Ludens has been established by Serra Eren Sarıoglu and Nazlı Kalfa Baş, who are the authors of this report. The report, which is written in Turkish, is a self-published, independent and without peer-review report. It can be sent upon request.
} 
As can be seen, the findings of Xiong et al. (2010) are very different from those from Brinson et al.'s (1991) study, which concludes that active management decisions did little to improve performance. Aglietta et al. (2012) determined that active management is the greatest source of U.S. pension funds' performance; it explains a much higher share of the funds' return volatility (26 per cent on average) than do their strategic choices (4 per cent on average over all asset classes). This conclusion is consistent with Ibbotson and Kaplan (2000) and Xiong et al. (2010). In our study, we adopt the method of Xiong et al.(2010) in order to exclude the impact of market movements across time on total fund returns.

For Canadian balanced and equity mutual funds, $\mathrm{Li}$ (2014) found that active management plays a more important role in explaining both intra- and inter-fund return variations than investment policy after controlling for market effects. He found that investment policy only explains one-third and one-fourth of total return variations for balanced and equity funds, respectively. Active management explains 5 per cent and 15 per cent more than investment policy in intra-fund return variations for balanced and equity funds, respectively.

Another criticism of the BHB article is the use of fixed-weight asset allocation. Jahnke (1997) argues that a static asset allocation policy makes no economic sense. In contrast to BHB, the return-based style analysis proposed by Sharpe (1992) was used by Xiong et al. (2010) and Ibbotson and Kaplan (2000).

Vardharaj and Fabozzi (2007) also examined the effect of different periods on explanatory power. They divided their 10-year investigation period into two equal sub-periods. They reported that explanatory power showed no significant change between sub-periods.

In this article, we explore the relative importance of asset allocation policy and active management in explaining the return variations for Turkish equity and balanced pension funds for the period July 2007 to July 2017. This study is the first that investigates this issue in Turkish pension funds. Most of the studies on this subject have examined markets in developed countries. Hence, the originality of the study is in its determination of the relative importance of asset allocation and active management in explaining the return variations in an emerging market. The remainder of this paper is as follows. Section II presents the data and methodology used. Section III represents the empirical results obtained. Finally, a conclusion is provided in Section IV.

\section{Data}

We selected twoportfolio peer groups for our analysis: equity pension funds and balanced pension funds. Our sample period is July 2007 - July 2017. We used 5 years and 10 years of net of fees monthly return data. We searched for all the funds that had existed for at least 5 years and 10 years as of the end of July 2017. The sample sizes for the 5-year analysis are 19 and 25 for equity and balanced pension funds, respectively. For the 10-years analysis, we employed 10 equity and 12 balanced pension funds. Note that the 5-year samples are relatively larger than the 10-year samples as the pension fund industry in Turkey is growing every year. The total Net Asset Value (NAV) of our 5-year and 10-year samples are 5.129 and 3.465 million USD, respectively. The 5-year sample represents 85 per cent and the 10-year sample 58 per cent of all equity and balanced funds in the Turkish pension fund universe. Our samples are sufficiently large to allow for interpretation of the results in our analysis. Table 1 provides the number and Net Asset Values of total equity and balanced pension funds in the Turkish pension fund universe as well as the ones used in this paper.

Table 1. Number and Net Asset Values (NAVs) of Pension Funds in Equity and Balanced Categories for the 10-Year and 5-Year Samples

\begin{tabular}{|c|c|c|c|}
\hline Number of Funds & $\begin{array}{c}\text { Turkish Pension Fund } \\
\text { Universe }\end{array}$ & 5-Year Sample & $\begin{array}{l}\text { 10-Year } \\
\text { Sample }\end{array}$ \\
\hline Equity Pension Funds & 19 & 19 & 10 \\
\hline Balanced Pension Funds & 43 & 25 & 12 \\
\hline Total & 62 & 44 & 22 \\
\hline \multicolumn{4}{|l|}{$\begin{array}{l}\text { NAV of Funds (million USD) (as of July } \\
31^{\text {st }}, 2017 \text { ) }\end{array}$} \\
\hline Equity Pension Funds & 1,138 & 1,074 & 800 \\
\hline Balanced Pension Funds & 4,874 & 4,055 & 2,664 \\
\hline Total & 6,012 & 5,129 & 3,465 \\
\hline Percentage of total pension fund universe & & $85 \%$ & $\mathbf{5 8 \%}$ \\
\hline
\end{tabular}


In our analyses, funds that no longer exist are also included in the sample as long as they cover the minimum number of years. Thus, our sample is, to a large extent, free of survivorship bias.

Following Vardharaj and Fabozzi (2007), we performed time series regressions on two sub-periods to investigate whether there is a significant difference in explanatory power. In order to verify whether the explanatory power of market, policy or active management has changed, we divided the 10 years into two equal sub-periods (July 2007July 2012 and August 2012-July 2017) and performed separate analyses for these sub-periods.

We also collected the monthly returns of benchmark indices to perform the return-based style analysis (RBSA) of Sharpe (1992) in order to obtain the asset allocation policy returns of the funds. Table 2 lists both the benchmark indices and the asset classes that the indices represent for equity and balanced pension funds. We obtained fund and index data from Finnet and Rasyonet, private data providers that are widely used in Turkey. The values of MSCI indices are from the MSCI website.

Table 2. Asset Classes and Benchmark Indices

This table lists the benchmark indices that represent the asset classes in which Turkish equity and balanced pension funds are invested in panel A and B, respectively. For the Turkish equity pension funds, we used four style factors, government bond index and cash. For the balanced funds we used 10 stock and bond benchmarks and cash.

\begin{tabular}{|c|c|}
\hline \multicolumn{2}{|c|}{ Panel A: Asset Classes and Benchmark Indices for Equity Pension Funds } \\
\hline Asset Class & Benchmark Index \\
\hline Turkish Government Bonds & $\begin{array}{l}\text { BIST- KYD Government Debt Securities ALL } \\
\text { Index }\end{array}$ \\
\hline Turkish Large Value Stocks & MSCI Turkey Large Value Index \\
\hline Turkish Large Growth Stocks & MSCI Turkey Large Growth Index \\
\hline Turkish Small and Medium Value Stocks & MSCI Turkey SMID Value Index \\
\hline Turkish Small and Medium Growth Stocks & MSCI Turkey SMID Growth Index \\
\hline Cash & BIST- KYD Repo Net Index \\
\hline \multicolumn{2}{|c|}{ Panel B: Asset Classes and Benchmark Indices for Balanced Pension Funds } \\
\hline Asset Class & Benchmark Index \\
\hline Government Long-Term Bonds & $\begin{array}{l}\text { BIST - KYD Government Debt Securities } 547 \\
\text { Days }\end{array}$ \\
\hline Government Medium-Term Bonds & $\begin{array}{l}\text { BIST - KYD Government Debt Securities } 365 \\
\text { Days }\end{array}$ \\
\hline \multirow[t]{2}{*}{ Government Short-Term Bonds } & $\begin{array}{l}\text { BIST - KYD Government Debt Securities } 91 \\
\text { Days }\end{array}$ \\
\hline & $\begin{array}{l}\text { BIST - KYD Government Debt Securities } 182 \\
\text { Days }\end{array}$ \\
\hline \multirow[t]{2}{*}{ Turkish Government Eurobonds } & $\begin{array}{l}\text { BIST- KYD Government Eurobond US Dollar } \\
\text { TL }\end{array}$ \\
\hline & BIST- KYD Government Eurobond Euro TL \\
\hline Turkish Large Value Stocks & MSCI Turkey Large Value Index \\
\hline Turkish Large Growth Stocks & MSCI Turkey Large Growth Index \\
\hline Turkish Small and Medium Value Stocks & MSCI Turkey SMID Value Index \\
\hline Turkish Small and Medium Growth Stocks & MSCI Turkey SMID Growth Index \\
\hline Cash & BIST- KYD Repo Net Index \\
\hline
\end{tabular}


Table 3. Decomposition of Time-Series Total Return Variations in Terms of Average $R^{2} s$

\begin{tabular}{|c|c|c|c|c|c|}
\hline Average $R^{2}($ per cent) & $\begin{array}{r}\text { Market } \\
\text { Movement: } \\
\mathbf{R}_{\text {it,t }} \text { VS. } \mathbf{M}_{\mathbf{t}} \\
\end{array}$ & $\begin{array}{r}\text { Asset } \\
\text { Allocation } \\
\text { Policy: } \\
\text { R }_{\mathrm{it}, \mathrm{t}} \mathbf{V S .} \mathbf{P}_{\mathrm{it}, \mathrm{t}-} \\
\mathbf{M}_{\mathbf{t}} \\
\end{array}$ & $\begin{array}{r}\text { Active } \\
\text { Management: } \\
\mathbf{R}_{\mathrm{it}, \mathrm{t}} \mathbf{v S} . \mathbf{R}_{\mathrm{it}, \mathrm{t}}-\mathbf{P}_{\mathrm{i}, \mathrm{t}}\end{array}$ & $\begin{array}{r}\text { Interaction } \\
\text { Effect }\end{array}$ & Total \\
\hline \multicolumn{6}{|l|}{ Equity Pension Funds } \\
\hline 10-year sample & 98 & 3 & 3 & -4 & 100 \\
\hline First-half sample & 99 & 3 & 3 & -5 & 100 \\
\hline Second-half sample & 99 & 7 & 3 & -9 & 100 \\
\hline 5-year sample & 98 & 7 & 4 & -9 & 100 \\
\hline \multicolumn{6}{|l|}{$\begin{array}{l}\text { Balanced Pension } \\
\text { Funds }\end{array}$} \\
\hline 10-year sample & 89 & 31 & 13 & -34 & 100 \\
\hline First-half sample & 89 & 35 & 13 & -37 & 100 \\
\hline Second-half sample & 94 & 17 & 7 & -19 & 100 \\
\hline 5-year sample & 87 & 29 & 12 & -28 & 100 \\
\hline
\end{tabular}

Table 4. Decomposition of Time-Series Excess Market Return Variations in Terms of Average $\mathbf{R}^{2} \mathbf{s}$

\begin{tabular}{|c|c|c|c|c|}
\hline Average $\mathbf{R}^{2}$ (per cent) & $\begin{array}{r}\text { Excess Market } \\
\text { Asset Allocation } \\
\text { Policy: } \\
\mathbf{R}_{\mathrm{it}, \mathrm{t}-\mathbf{M}_{\mathrm{t}} \text { vs. } \mathbf{P}_{\mathrm{it}, \mathrm{t}} \text { - }} \mathbf{M}_{\mathrm{t}} \\
\end{array}$ & $\begin{array}{r}\text { Active } \\
\text { Management: } \\
\mathbf{R}_{\mathrm{it}, \mathrm{t}}-\mathbf{M}_{\mathrm{t}} \text { vs. } \mathbf{R}_{\mathrm{it,t},}- \\
\mathbf{P}_{\mathrm{i}, \mathrm{t}}\end{array}$ & $\begin{array}{r}\text { Interaction } \\
\text { Effect }\end{array}$ & Total \\
\hline \multicolumn{5}{|l|}{ Equity Pension Funds } \\
\hline 10-year sample & 4 & 35 & 61 & 100 \\
\hline First-half sample & 5 & 33 & 62 & 100 \\
\hline Second-half sample & 7 & 32 & 62 & 100 \\
\hline 5-year sample & 8 & 36 & 56 & 100 \\
\hline \multicolumn{5}{|l|}{$\begin{array}{l}\text { Balanced Pension } \\
\text { Funds }\end{array}$} \\
\hline 10-year sample & 26 & 41 & 33 & 100 \\
\hline First-half sample & 38 & 34 & 28 & 100 \\
\hline Second-half sample & 17 & 45 & 38 & 100 \\
\hline 5-year sample & 31 & 43 & 26 & 100 \\
\hline
\end{tabular}

\section{Methodology}

\subsection{Decomposing The Returns}

In order to examine empirically the effects of investment choices on the performance of funds, two return components of the funds can be distinguished: policy (asset allocation policy) return and active return. Before describing the mathematics of our study, the notation must be defined:

$R_{i, t}=$ Total return for fund $i$ in period $t$

$P_{i, t}=$ Policy return for fund $i$ in period $t$

$M_{t}=$ Market return in period $t$

$R_{i, t}-M_{t}=$ Excess market fund return for fund $i$ in period $t$

$P_{i, t}-M_{t}=$ Excess market policy return for fund $i$ in period $t$

$R_{i, t}-P_{i, t}=$ Active management or active return for fund $i$ in period $t$

The following equation express the total return of the fund in terms of policy return:

$$
R_{i, t}=b_{0}+b_{1} P_{i, t}+\varepsilon_{i, t}
$$


In the equation, $b_{0}$ and $b_{1}$ are the regression coefficients and $\varepsilon_{i, t}$ is the residual return, which is the difference between the realized and the predicted fund returns. This equation has been used in some of the previous timeseries studies of asset allocation and is referred as "total return time-series regression".

However, it is well-known that the results of these analysis are dominated by the overall market movement as the formula uses total fund return. The more applicable approach is to use excess market fund returns instead of total fund returns. Thus, Equation 1 can be adapted into a regression equation for excess market fund returns:

$$
R_{i, t}-M_{t}=b_{0}+b_{1}\left(P_{i, t}-M_{t}\right)+\varepsilon_{i, t}
$$

In the previous studies analyzing the relative importance of asset allocation policy and active management, Equation 2 is referred as the "excess market return time-series regression".

Thus, the total return of a fund can be decomposed as:

(1) return related to the overall market,

(2) return related to asset allocation policy,

(3) return related to active management, which embodies the security selection and market timing abilities of fund managers.

We can express the decomposition of total fund return as follows:

$$
R_{i, t}=M_{t}+\left(P_{i, t}-M_{t}\right)+\left(R_{i, t}-P_{i, t}\right)
$$

In equation 3, $\left(P_{i, t}-M_{t}\right) \operatorname{and}\left(R_{i, t}-P_{i, t}\right)$ refer to asset allocation policy return and active return, respectively. Likewise, fund excess market return can be decomposed as follows:

$$
R_{i, t}-M_{t}=\left(P_{i, t}-M_{t}\right)+\left(R_{i, t}-P_{i, t}\right)
$$

Following Xiong et.al (2010), we calculate the market return as the equally weighted sum of returns from all funds in the applicable fund universe.

\subsection{Time-Series Analysis}

In order to answer the question of how much of the variability of returns across time is explained by policy, we conducted time-series analyses. Before beginning the time-series analysis, we need the 'asset allocation policy returns' of the funds. We employed the RBSA method of Sharpe (1992) and regressed each fund's total returns against the returns of asset-class benchmarks to determine its exposures. This standard technique uses the returns of funds in order to explain the systematic exposure of each portfolio to benchmark (asset class) returns. The regression equation is as follows:

$$
R_{i}=\propto+\beta_{i 1} X_{1}+\beta_{i 2} X_{2}+\cdots+\beta_{n} X_{n}
$$

subject to $\sum_{j=1}^{k} \beta_{j}=1,0 \leq \beta_{j} \leq 1, \mathrm{j}=1,2, \ldots, \mathrm{n}$

$R_{i}$ represents fund's total return, $X_{j}$ is the return of the different asset classes and $\beta_{i j}$ is the vector of coefficients of exposure to each of the asset classes.

RBSA is a constrained OLS (ordinary least squares) regression which estimates the b-parameters ( $\beta_{i j}$ coefficients) that minimize the residual variance of the model with two restrictions: The first one is that all of the portfolio must be invested; that is the weights must sum to 1 (portfolio constraint). The second restriction is that negative bparameters must not be admitted (positivity constraint).

The estimated coefficients can be treated as a fund's real asset allocation (policy) weights. The policy return of the fund over a given period of time is computed from these policy weights and returns on asset class benchmarks are as follows:

$$
P_{i, t}=\beta_{i 1} X_{1}+\beta_{i 2} X_{2}+\cdots+\beta_{n} X_{n}
$$

Firstly, we conducted total return time-series regressions based on Equation 3. The dependent variable was regressed on each of the independent variables separately. Thereafter, we found the average R-square values from the fund-by-fund regressions.

Since the regressions based on Equation 3 do not remove the effect of market movements on total returns, we next run excess return time-regressions based on Equation 4 to find the impacts of asset allocation policy and active management after eliminating market effects. Again the dependent variable was regressed on each of the independent variables separately and the average R-square values were computed. 


\section{Results}

We present the results of our time-series analysis of total returns and time-series analysis of returns of funds in excess of market returns. First, we analyzed the contribution of the three sources of performance to the total variance of the funds. These sources of performance are: market movement, asset allocation policy and active management. Table 1 shows the average R-square of the three components for each fund category.

The most significant observation from Table 1 is that market movement dominates both asset allocation policy and active portfolio management no matter the observation period is. This component of performance accounts for about 98 per cent of the total return variations in equity pension funds and 89 per cent for balanced funds.

Our finding is consistent with the findings of Xiong et.al (2010), Aglietta et.al. (2012) and Li (2014). Xiong et.al. (2010) found that, in their sample of US mutual funds, nearly 80 per cent of the funds' returns are explained by market movements. Aglietta et.al. (2012) showed that the volatility of 143 US defined-benefit pension funds' returns is mainly explained by the overall market movement. The findings of $\mathrm{Li}$ (2014) provide evidence for the dominance of market movement in the returns of Canadian balanced and equity mutual funds. However, we should keep in mind some important differences when we are comparing our study with these other three similar studies. The most important difference is that all of these three studies use developed market data. The market dynamics of the emerging markets are much more different than the developed markets'. In most of the emerging markets, including Turkey, the economic conditions are distinct and the capital markets are publicly dominated. In order to ensure that mutual funds' portfolios are sufficiently liquid and well diversified, law and regulations enforce some limitations on their portfolios. As can be seen from Table 1, the market movement effect in equity funds is higher than the effect in balanced funds. This can be explained by restrictions due to regulations in the asset class investment of equity funds. Turkish equity pension funds must invest on average 80 per cent of their portfolios in equities. There is no such limit in balanced pension funds.

The interaction effect denotes the effect that is not explained by the independent variables. Although the rate is no more than 10 per cent of equity funds, it is high in balanced pension funds. The reason for these high rates might be the increased percentage of corporate bond investments in these funds. We could not assign any indices in our analysis for corporate bond investments. As the secondary market of corporate bonds are still illiquid in Turkey, the indices of these instruments do not represent the returns of the bonds.

Several previous studies showed that asset allocation policy has a high explanatory power that is dominated by market movements embedded in the total returns. A time-series analysis of excess market returns eliminates the overall market movement in the total return regressions. Table 2 presents the findings of these regressions. We decomposed the funds' excess market returns into excess market asset allocation policy returns and active returns in terms of average $\mathrm{R}^{2} \mathrm{~s}$.

For the equity pension funds, active management accounts for nearly 35 per cent of the fund excess market return variations which is higher than the policy excess market returns in all of the observation periods. In contrast to the findings of Xiong et al. (2010), the explanatory power of active management and policy management is not equal in equity pension funds. This conflicting result can arise from the differences in the market dynamics between a developed and an emerging market.

When it comes to balanced pension funds, the picture changes. Except for the second-half of the 10-year sample period, active management and policy management have nearly an equal amount of explanatory power on the variations of fund returns. The $\mathrm{R}^{2} \mathrm{~s}$ in the 5-year sample are very much close to the 10 -year sample values. Xiong et al. (2010) also find an almost equal explanatory power between asset allocation policy and active management in their one-window observation period (10-year sample, May 1999 - September 2009).

\section{Conclusion}

The debate about the importance of asset allocation in the total returns of funds has a long history in finance arena and this paper aims to provide some evidence from an emerging market perspective.

In order to determine the relative importance of asset allocation and active management in explaining the return variations in Turkish balanced and equity pension funds, we conducted two different analyses. First of all, we decomposed the fund's total return as (1) the return from the market movements, (2) the asset allocation policy return in excess of market return, and (3) the return from the active management. We found that market return is the dominant determinant of total return variations. 
The evidence from an emerging market side confirms the widely held belief that market movement and asset allocation policy leave a little room for active management. However, when we compared the effect of market movement in equity and balanced pension funds, we found that the effect is less in balanced funds. The higher active management effect in the returns of balanced funds can be explained by having no investment restrictions of the regulations in this category of pension funds, contrary to equity pension funds.

Secondly, we performed a refined analysis which removes the dominance of market movement component of total return. The results of this analysis reveal a different picture. This time we decomposed the fund's excess market returns into (1) excess market asset allocation policy returns and (2) active returns. Our findings show that, similar with the findings of Xiong et al. (2010), the active management and asset allocation have nearly an equal amount of explanatory power on the variations of balanced pension fund returns. However, for the equity pension funds does the active management provide a significantly higher performance than asset allocation policy.

In this study, we shed new light on pension funds' sources of performance using a unique database from Turkish capital market. The main result from our empirical investigation is that market movement is the dominant factor in the total return. However, the effect of the dominance changes depending on the pension fund category. The less restricted funds in their investment decisions perform higher active management ability.

Regarding the future line of research, employing other emerging markets' data may provide findings that can be used to compare with the results of this study.

\section{References}

Aglietta, M., Briere, M, Rigot, S. and Signori, O. (2012). Rehabilitating the Role of Active Manamegent for Pension Funds. Solvey Brussels School, Centre Emile Bernheim, CEB Working Paper No 12/018, 1-25.

Brinson, G.P. , Hood, L.R. and Beebower, G.L. (1986). Determinants of Portfolio Performance. Financial Analysts Journal, July-August, 39-44.

Brinson, G.P. , Hood, L.R. and Beebower, G.L. (1991). Determinants of Portfolio Performance II: An Update. Financial Analysts Journal, May-June, 40-48.

Hensel, C.R., Ezra, D.D and Ilkiw, J.H. (1991). The Importance of the Asset Allocation Decision. Financial Analysts Journal, July-August, 65-72.

Ibbotson, R.G. and Kaplan, P.D. (2000). Does Asset Allocation Policy Explain 40, 90, or 100 Percent of Performance? Financial Analysts Journal, January-February, 26-33.

Jahnke, W.W. (1997). The Asset Allocation Hoax. Journal of Financial Planning. February, 109-113.

Li, Y. (2014). The Relative Importance of Investment Policy and Active Management in Explaining Canadan Mutual Fund Return Variations and Performance. A Thesis in the Department of John Molson School of Business. Canada.

Sharpe, W.F. (1992). Asset Allocation: Management Style and Performance Measurement. Journal of Portfolio Management 18, 7-19.

Vardaraj, R. and Fabozzi, F.J.(2007). Sector, Style, Region: Explaning Stock Allocation Performance. Financial Analysts Journal. Vol: 63. No: 3, 59-70.

Xiong, J. X., Ibbotson, R.G., Idzorek, T.M. and Chen, P. (2010). The Equal Importance of Asset Allocation and Active Management. Financial Analysts Journal. Vol: 66. No: 2, 1-9. 